\title{
Bridging the treatment gap for Indigenous Australians
}

\author{
Demands for efficiency should not be met at the expense of equity
}

$\mathrm{D}$ espite countless reports over decades about the health disadvantages of Indigenous Australians, attention has only recently been turned to remedying disparities in the provision and quality of health care. A report in this issue of the Journal by Coory and Walsh about access to coronary procedures (page 507$)^{1}$ adds to a growing body of evidence that Indigenous Australians do not receive the same level of care as other Australians..$^{2-4}$ How might clinicians be contributing inadvertently to this "treatment gap"? And how can they remedy it?

Clinical decisions are based on imperfect information. To each clinical encounter, doctors bring prior beliefs about the likely nature of the condition. These beliefs differ according to the patient's age, sex, socioeconomic status and ethnicity. They influence diagnosis, investigations and treatment. With identical descriptions of pain, a doctor is more likely to diagnose cardiac ischaemia in an elderly, sedentary, obese man than in a young, active woman of normal weight. Such stereotyping is helpful - and, indeed, promotes efficient practice - when it is based on epidemiology, statistical likelihood and best evidence. However, when incorrect, inappropriate and often implicit beliefs about the behav-

iour or health of a particular group are applied to individuals, stereotyping can be harmful.

Uncertainty increases with patients who speak a different language or belong to a different cultural group. This, in turn, can lead to unhelpful, even harmful stereotyping. The experience of an Aboriginal politician who recently underwent emergency surgery demonstrates this. "I have had problems with my stomach and my abdomen for years. They were saying it was a problem with my kidneys and now that I have had this surgery on my bowels, they have found out that my kidneys are perfect," she said. "So when I have gone to doctors complaining about illness over many years, I suppose they have taken my genetic heritage as a Tiwi Islander and thought it was renal." ${ }^{5}$ Delays in diagnosis and treatment caused by such stereotyping might be partly responsible for Indigenous Australians' poorer health outcomes.

In the United States, concerns about the quality of health care received by racial and ethnic minorities compared with white Americans prompted Congress to request an investigation by the Institute of Medicine (IOM). Their landmark report, Unequal treatment: confronting racial and ethnic disparities in health care, found convincing evidence that racial and ethnic disparities exist across a wide range of conditions and health services and are associated with poorer outcomes. ${ }^{6}$

The report made several recommendations relevant to Australia, including cross-cultural training, use of interpreter services, and training more health care providers from ethnic and racial minority backgrounds. ${ }^{6}$ However, this might not suffice. Doctors who treat black Americans are less likely than those who treat white Americans to be "board certified" (ie, fully qualified) specialists. They are also more likely to report difficulty in arranging access to consultants, diagnostic imaging, and nonemergency hospital admission. ${ }^{7}$ In other words, doctors who treat black patients have less power, fewer resources, and possibly less training than doctors who treat whites. Is this also true in Australia?

The IOM report defined disparities as racial or ethnic differences in the quality of health care not due to clinical need, patient preference or appropriateness of intervention. ${ }^{6}$ In Australia, these three factors have repeatedly been suggested as reasons for the treatment gap. Coory and Walsh suggest that the prevalence and severity of comorbidities may have a major impact on lower rates of coronary procedures and make providers question the appropriateness of such interventions. ${ }^{1}$ They note that selection favours lower-risk patients. However, even after controlling for the presence of comorbidities, Indigenous Australians still had significantly fewer interventions. With respect to patient preference, some commentators have suggested that, because Aboriginal people treated for chronic kidney disease fare poorly, they prefer not to be treated, ${ }^{8}$ but this hypothesis is contradicted by growing community activism to secure dialysis services in remote areas. ${ }^{9,10}$

A crucial issue is the increasing conflict between "efficiency" and equity. With increasing demands on health services, doctors attempt to maximise efficient use of scarce resources. Based on the mantra of "evidence-based medicine", doctors perform more selective procedures and strive for lower rates of complications. A recent editorial suggested that people who cannot stop smoking should be excluded from a range of therapeutic interventions because of their higher risk of postoperative complications. ${ }^{11}$ Similar exclusions could also be applied to other groups, such as obese people. While this approach might increase "efficiency", applying such standard criteria would greatly reduce Indigenous Australians' access to beneficial interventions. Perhaps a higher complication rate is acceptable in the overall context of Indigenous Australians' relative need for health care. Recovery from postoperative complications might be preferable to death without surgery.

The responsibility for reducing ethnic disparities rests primarily with the health care system and its providers. System-level changes are clearly required, such as adequate funding for primary care, an adequate Indigenous health workforce, and improvements in the interface between primary care and specialist services. ${ }^{1,6,12}$ Clinicians have a central role to play in advocating for such changes.

Because patients should be part of the solution, the IOM report recommends the development of appropriate education for patients in areas such as when and how to access health care, and how to participate effectively in clinical decision-making. ${ }^{6}$ However, most patients, in particular Indigenous Australian patients, are relatively powerless compared with doctors and "the system".

In Australia, the political debate about Indigenous health and development is framed in terms of "mutual obligation". If we 


\section{UNEQUAL TREATMENT - EDITORIAL}

clinicians and researchers are to fulfil our obligation, we must first understand how we might inadvertently be contributing to the problem and then take steps to bridge the treatment gap.

Joan Cunningham Principal Research Fellow Menzies School of Health Research, and Institute of Advanced Studies Charles Darwin University, Casuarina, NT joan.cunningham@menzies.edu.au

Alan Cass

Head, Renal Program The George Institute for International Health, Sydney, NSW

Peter C Arnold Former GP, PO Box 280, Edgecliff, NSW

Acknowledgements: Joan Cunningham is supported by an NHMRC Career Development Award \#283310. Alan Cass is a recipient of an RACP Jacquot Research Establishment Award.

1 Coory M, Walsh WF. Rates of percutaneous coronary interventions and bypass surgery after acute myocardial infarction in indigenous patients. Med J Aust 2005; 182: 507-512.

2 Cunningham J. Diagnostic and therapeutic procedures among Australian hospital patients identified as Indigenous. Med J Aust 2002; 176: 58-62.
3 Hall SE, Bulsara CE, Bulsara MK, et al. Treatment patterns for cancer in Western Australia: does being Indigenous make a difference? Med $J$ Aust 2004; 181: 191-194.

4 Cass A, Cunningham J, Snelling $P$, et al. Renal transplantation for Indigenous Australians: identifying the barriers to equitable access. Ethn Health 2003; 8: 111-119.

5 Hinde S. Minister slams her own health system. Northern Territory News 2005; 4 Apr: 1.

6 Institute of Medicine. Unequal treatment: confronting racial and ethnic disparities in health care. Washington, DC: National Academy of Sciences, 2003. Available at: http://www.nap.edu/books/030908265X/html/ (accessed Apr 2005).

7 Bach PB, Pham HH, Schrag D, et al. Primary care physicians who treat blacks and whites. N Engl J Med 2004; 351: 575-584.

8 Willis J. Fatal attraction: do high-technology treatments for end-stage renal disease benefit Aboriginal patients in central Australia? Aust $J$ Public Health 1995; 19: 603-609.

9 Rivalland P. More than machine and medicine. Alice Springs: Western Desert Nganampa Walytja Palyantjaku Tjutaku Aboriginal Corporation (WDNWPT), 2005.

10 Loff B, Cordner S. Aboriginal people trade land claim for dialysis. Lancet 1998; 352: 1451.

11 Peters MJ, Morgan LC, Gluch L. Smoking cessation and elective surgery: the cleanest cut. Med J Aust 2004; 180: 317-318.

12 Ring IT, Brown N. Indigenous health: chronically inadequate responses to damning statistics. Med J Aust 2002; 177: 629-631. 